\title{
Alendronate promotes osteoblast differentiation and bone formation in ovariectomy-induced osteoporosis through interferon- $\beta$ /signal transducer and activator of transcription 1 pathway
}

\author{
XIAOQING MA ${ }^{1}$, ZHONGYANG XU $^{2}$, SHAOFENG DING $^{1}$, GUANGKUN YI $^{2}$ and QIAN WANG $^{2}$
}

\author{
Departments of ${ }^{1}$ Endocrinology and ${ }^{2}$ Spine Surgery, Jining No. 1 People's Hospital, Jining, Shandong 272000, P.R. China
}

Received August 17, 2016; Accepted May 19, 2017

DOI: 10.3892/etm.2017.5381

\begin{abstract}
Alendronate is commonly used for the treatment of postmenopausal osteoporosis; however, the underlying pathological molecular mechanisms of its action remain unclear. In the present study, the alendronate-treated signaling pathway in bone metabolism in rats with ovariectomy induced by osteoporosis was investigated. Rats with osteoporosis were orally administered alendronate or phosphate-buffered saline (control). In addition, the interferon- $\beta$ (IFN- $\beta$ )/signal transducer and activator of transcription 1 (STAT1) signaling pathway was investigated in osteoblasts following treatment with alendronate in vitro and in vivo. During the differentiation period, IFN- $\beta(100 \mathrm{ng} / \mathrm{ml})$ was used to treat the osteoblast cells, and the activity, viability and bone metabolism-associated gene expression levels (STAT1, p-STAT1, Fra1, TRAF6 and SOCS1) were analyzed in osteoblast cells. Histopathological changes were used to evaluate osteoblasts, osteoclasts, inflammatory phase of bone healing and osteonecrotic areas. The results demonstrated that alendronate significantly inhibited the activity of osteoporotic osteoclasts by stimulating expression of IFN- $\beta$, as well as markedly improved the viability and activity of osteoblasts compared with the control group. In addition, alendronate increased the expression and phosphorylation levels of STAT1 in osteoclasts, enhanced osteoblast differentiation, upregulated the expression levels of alkaline phosphatase and osteocalcin, and increased the expression of osteoblast differentiation-associated genes (osteocalcin, osterix and Runx2). Inhibition of IFN- $\beta$ expression canceled the benefits of alendronate-mediated osteoblast differentiation. Notably, alendronate enhanced bone formation in rats with osteoporosis induced by ovariectomy. In conclusion, these
\end{abstract}

Correspondence to: Dr Qian Wang, Department of Spine Surgery, Jining No. 1 People's Hospital, 6 Health Road, Jining, Shandong 272000, P.R. China

E-mail: wangqiandoctor@163.com

Key words: alendronate, osteoporosis, osteoblast, interferon- $\beta$, signal transducer and activator of transcription 1 findings suggest that alendronate can regulate osteoblast differentiation and bone formation in rats with osteoporosis induced by ovariectomy through upregulation of IFN- $\beta /$ STAT1 signaling pathway.

\section{Introduction}

The human skeletal system comprises highly dynamic tissue that exhibits continuous bone formation by osteoblasts and bone resorption by osteoclasts to maintain homeostasis (1). Previous studies have suggested that dysfunction of remodeling and metabolism of osteoblasts and osteoclasts are associated with the progression of osteoporosis in individuals aged $>50$ years $(2,3)$. Osteoporosis exhibits complex pathology and etiology, and is considered as a multifactorial polygenic disease associated with environmental, hormonal, nutritional and genetic factors. Studies have indicated that estrogen concentration is correlated with the pathogenesis of osteoporosis by regulating bone homeostasis and preventing postmenopausal bone loss $(4,5)$. Although numerous perspective studies on postmenopausal osteoporosis have been reported, the molecular mechanisms of the pathogenesis induced by postmenopausal osteoporosis are not completely understood.

The clinical consequences of osteoporosis include fractures in the upper extremities, hip and even spine, which result in the loss of function and independence, impaired quality of life, as well as increased morbidity and mortality (6-8). Various treatments for postmenopausal osteoporosis, including farnesyl pyrophosphate synthase inhibitor, have been proposed in a large number of preclinical and clinical studies (9-11). In addition, the downregulation of levels of osteoassociated hormones have been detected in the blood plasma of postmenopausal women with and without osteoporosis in clinical trials $(12,13)$. Furthermore, comprehensive treatments with anti-resorptive agents, such as alendronate, have been investigated for the prevention of new non-vertebral fractures in patients with postmenopausal osteoporosis (14). In the present study, the alendronate-mediated benefits and mechanism for the treatment of rats with ovariectomy-induced osteoporosis were investigated.

Previous studies have demonstrated the efficacy of long-term alendronate treatment on postmenopausal osteoporosis and 
bone material properties $(13,15)$. In addition, arterial stiffness was improved following monthly bisphosphonate treatment in women with postmenopausal osteoporosis (16). The effects of other drug treatments on endothelial function, glucose metabolism and inflammation markers have also been investigated in patients with postmenopausal osteoporosis (17-19). Furthermore, a previous study examined the effects of short-term treatment with alendronate $(70 \mathrm{mg}$; once-a-week) in women with postmenopausal osteoporosis, determined by bone turnover markers, and suggested that alendronate treatment was beneficial in these patients (18).

Signal transducer and activator of transcription 1 (STAT1) signaling pathway is strongly activated by interferon- $\beta$ (IFN- $\beta$ ) in the pathogenesis and progression of osteoporosis, and previous results contributed to further understanding the pathological signaling pathways involved in osteoporosis (20). The importance of STAT1 gene expression in monocytes has been reported, and the progression of osteoporosis was observed to be regulated by the expression and phosphorylation levels of STAT1 (21). These findings suggest that STAT1 gene expression may be associated with the initiation and development of osteoporosis.

In the present study, the therapeutic effects and molecular mechanism of alendronate were investigated in osteoblast cells and in rats with osteoporosis induced by ovariectomy. The potential involvement of the IFN- $\beta$ /STAT1 signaling pathway mediated by alendronate in the progression of ovariectomy-induced osteoporosis was also examined. The findings suggested that alendronate regulated osteoblast differentiation and bone formation through upregulation of IFN- $\beta /$ STAT1 pathway in the rats. These results may contribute to the clinical treatment of patients with postmenopausal osteoporosis.

\section{Materials and methods}

Ethical statement. The present study was conducted in strict accordance with the guidelines for the Care and Use of Laboratory Animals of Jining No. 1 People's Hospital (Jining, China). All experimental protocols and animals were approved by Ethics Committee of the Animal Experiments Defense Research of Jining No. 1 People's Hospital (Jining, China). All surgery and euthanasia procedures aimed to minimize animal suffering.

Animal study. Female Wistar albino rats (age, 6-8 weeks) were purchased from Shanghai Slack Experimental Animals Co., LTD (Shanghai, China). Rats $(n=40)$ were fed under pathogen-free conditions and maintained in a controlled environment (temperature, $23 \pm 1^{\circ} \mathrm{C}$; humidity, 50-60\%), as well as an artificial simulation of $12 \mathrm{~h}$ light/dark cycles. All rats underwent oophorectomy in order to establish an osteoporosis model and to analyze the efficacy of alendronate treatment. Experimental procedures were conducted according to a previous study (22). The induction lasted 14 days and the mandibular cortical width was used as an indicator of osteoporosis to determine whether the model was successfully established (23). Rats with osteoporosis were randomly divided into two groups ( $\mathrm{n}=20$ in each group) and received treatment with alendronate $(2.5 \mathrm{mg} / \mathrm{kg}$; Sigma-Aldrich; Merck KGaA; Darmstadt, Germany) or phosphate-buffered saline
(PBS; $2.5 \mathrm{mg} / \mathrm{kg}$ ). The treatments were performed once a day in a total of 10 times. On day 60, the therapeutic efficacies of alendronate were analyzed according to a previous study (24).

Bone mineral density. Bone tissues were isolated from experimental animals according to previous study (25). Bone cells were obtained from bone tissues as previously described (26). A total of $1 \times 10^{5}$ bone cells were used to analyze bone mineral density. Bone mineral density of the tibia of experimental rats was analyzed with an automated software (N-Vivo 9.0; QSR International Ltd., Melbourne, Australia) and quantified for analysis of the efficacy of alendronate. All procedures were performed as previously described (27). Intermediate bone density was defined as $\mathrm{mg} / \mathrm{cm}^{3}$.

Measurement of alkaline phosphatase (ALP) activity. Osteoblasts were isolated from experimental mice as described previously (28) and cultured in 6 -well plates $\left(1 \times 10^{5}\right.$ per well) with alendronate at concentrations of $0,0.50,4.00,8.00$ and $16 \mathrm{mg} / \mathrm{ml}$ for $48 \mathrm{~h}$. The effect of alendronate treatment on osteoblasts cells was analyzed by performing ALP activity assays and ALP staining (Colorimetric Alkaline Phosphatase Assay kit; ab83369; Abcam; Cambridge, MA, USA) as described in a previous study (29).

Bone resorption assays. Mature osteoclasts and osteoblasts were isolated from experimental rats with ovariectomy-induced osteoporosis and cultured in the presence of $10^{-6} \mathrm{M}$ 1,25-dihydroxyvitamin $\mathrm{D}_{3}$ and $10^{-6} \mathrm{M}$ prostaglandin $\mathrm{E}_{2}$ (Sigma-Aldrich, Merck, Darmstadt, Germany) for 7 days. Next, the cells were treated with alendronate $(2 \mathrm{mg} / \mathrm{ml})$ or PBS $(2 \mathrm{mg} / \mathrm{ml})$ for $48 \mathrm{~h}$ at $37^{\circ} \mathrm{C}$. Subsequently, the minimum essential medium (MEM) was removed from the culture and cells were washed with PBS three times. Then, the total bone resorption was analyzed using ImagePro Plus version 4.0 (Media Cybernetics, Inc., Silver Spring, MD, USA).

Analysis of the effects of alendronate on osteoclast differentiation. Bone marrow cells (BMCs) were obtained from female Wistar albino rats as described previously (30) and cultured in MEM supplemented with $10 \%$ fetal bovine serum (FBS) for $48 \mathrm{~h}$ at $37^{\circ} \mathrm{C}$. The medium was removed, and fresh MEM was added before cells were cultured for $72 \mathrm{~h}$ in $10 \mathrm{ng} / \mathrm{ml}$ macrophage colony-stimulating factor (M-CSF; Sigma-Aldrich; Merck KGaA) at $37^{\circ} \mathrm{C}$. Tartrateresistant acid phosphatase (TRAP) activity was measured (Sigma-Aldrich; Merck KGaA; 387A-1KT) and used to examine the osteoclast differentiation (31).

Measurement of osteoblast viability. The viability of osteoblasts was analyzed in order to examine the effects of alendronate on osteoporosis, as descripted in a previous study (32). All experiments were performed in triplicate.

Reverse transcription-quantitative polymerase chain reaction (RT-qPCR) assays. Total RNA from the femurs of rats was extracted using RNAeasy Mini kit (Qiagen, Gaithersburg, MD, USA). The mRNA expression levels of osteocalcin, osterix, Runt-related transcription factor 2 (Runx2), TRAP, osteoblast differentiation factor (ODF), osteoprotegerin 
Table I. Sequences of primers were used in the present study.

Sequence

\begin{tabular}{lll}
\cline { 2 - 3 } Gene name & \multicolumn{1}{c}{ Reverse } & \multicolumn{1}{c}{ Forward } \\
\hline ALP & 5'-CTAGCTGCTCCTATGTCTCACATC-3' & 5'-GGTCAAGACCATTTGTAGGCTC-3' \\
TRAP & 5'-TGGTCATTTCTTTGGGG CTTATCT-3' & 5'-GCTACTTGCGGTTTCACTATGGA-3' \\
ODF & 5'-CACCTGGTTGCTGACTAATTGAGA-3' & 5'-CTTGCTGTCCGACCAAATA-3' \\
OPG & 5'-AACGGCAACACAGCTCACAAGAAC-3' & 5'-TGCTCGAAGGTGAGGTTAGCATGT-3' \\
COL1A1 & 5'-CACCAATCACCTGCGGTACAGAA-3' & 5'-CAGATCACGTCATCGCACAAC-3' \\
Osteocalcin & 5'-ACACTCCTCGCCCTATTG-3' & 5'-GATGTGGTCAGCCAACTC-3' \\
Runx2 & 5'-TCTGGAAAAAAAAGGAGG GACTATG-3' & 5'-GGTGCTCGGATCCCAAAAGAA-3' \\
Osterix & 5'-GGAGGTTTCACTCCATTCCA-3' & 5'-TAGAAGGAGCAAGGGGACAGAA-3' \\
Fra1 & 5'-ATGTACCGAGACTTCGGGGAACC-3' & 5'-CACTGTGTTGGCGTAGA-3' \\
TRAF6 & 5'-CAAGTGTCGTGCCAAGTGAT-3' & 5'-TTCCAGAAGTGCCAGGTTAATAC-3' \\
SOCS1 & 5'-GCCTGCTGGCCATCCTAA-3' & 3'-ACCGCCAGCACCACAGT-3' \\
$\beta$-actin & 5'-CATCTCTTGCTCGAAGTCCA-3' & 5'-ATCATGTTTGAGACCTTCAACA-3' \\
\hline
\end{tabular}

ALP, alkaline phosphatase; TRAP, tartrateresistant acid phosphatase; ODF, osteoblast differentiation factor; OPG, osteoprotegerin; COL1A1, collagen 1A1; Runx2, runt-related transcription factor 2; Fra1, Fos-related antigen 1; TRAF6, Tumor necrosis factor-receptor-associated factor 6; SOCS1, suppressor of cytokine signaling 1.

(OPG), collagen 1A1 (COL1A1), Fos-related antigen 1 (Fra1), TNF-receptor-associated factor 6 (TRAF6), suppressor of cytokine signaling 1 (SOCS1) and ALP in osteoblasts and osteoclasts were determined by RT-qPCR with $\beta$-actin as an endogenous control (33). All the forward and reverse primers were synthesized by Thermo Fisher Scientific, Inc. (Table I). PCR was performed as follows: Preliminary denaturation at $94^{\circ} \mathrm{C}$ for $2 \mathrm{~min}$, followed by 45 cycles of $95^{\circ} \mathrm{C}$ for $30 \mathrm{sec}$, the annealing temperature reduced to $57.5^{\circ} \mathrm{C}$ for $30 \mathrm{sec}$, and $72^{\circ} \mathrm{C}$ for $10 \mathrm{~min}$ in a total reaction volume of $20 \mu \mathrm{l}$ containing $50 \mathrm{ng}$ of genomic DNA, $200 \mu \mathrm{M}$ dNTP, 2.5 units of Taq DNA polymerase, and $200 \mu \mathrm{M}$ primers. Relative mRNA expression level changes were calculated by $2^{-\Delta \Delta \mathrm{Cq}}$ method (25). The results are expressed as the $\mathrm{n}$-fold way compared with the $\beta$-actin control.

Western blot assay and histological analysis. Osteoblasts from experimental rats with osteoporosis treated with alendronate or PBS were homogenized in lysate buffer. The supernatant of the mixture obtained by centrifugation at $6,000 \mathrm{x} \mathrm{g}$ for $10 \mathrm{~min}$ at $37^{\circ} \mathrm{C}$ and used for analysis of the target protein levels. Transmembrane protein was extracted using a Transmembrane Protein Extraction kit (71772-3; Qiagen) according to the manufacturer's instructions. SDS-PAGE assays were performed as previous described (34). For western blotting, primary antibodies: IFN- $\beta$ (1:1,000; ab77246; Abcam), STAT1 (1:1,000; ab31369; Abcam), pSTAT1 (1:1,000; ab30645; Abcam), $\beta$-actin (1:1,000; ab8226; Abcam) were added for $12 \mathrm{~h}$ at $4^{\circ} \mathrm{C}$ after blocking in 5\% skimmed milk for $1 \mathrm{~h}$ at $37^{\circ} \mathrm{C}$, followed by incubation with horseradish peroxidase-conjugated anti-rabbit IgG (1706515; Bio-Rad Laboratories, Inc., Hercules, CA, USA) were used at a 1:5,000 dilution for $24 \mathrm{~h}$ at $4^{\circ} \mathrm{C}$. The results were visualized using an enhanced chemiluminescence detection system (ChemiDoc ${ }^{\mathrm{TM}}$ Imaging Systems, Bio-Rad Laboratories, Inc.).
For histological analysis, experimental rats were anesthetized using intraperitoneal injection of sodium pentobarbital anesthesia (40 mg/kg; Invitrogen; Thermo Fisher Scientific, Inc.) and the femur was isolated from experimental rats after treatment with alendronate or PBS. Femur tissues were sectioned (4- $\mu \mathrm{m}$ thick), fixed using $10 \%$ formaldehyde for $15 \mathrm{~min}$ at $30^{\circ} \mathrm{C}$ followed by embedding in paraffin wax. Hematoxylin-eosin staining for $120 \mathrm{~min}$ at $30^{\circ} \mathrm{C}$ was used to analyze the bone quality and density using a microscope (Olympus Corporation; Tokyo, Japan) at a magnification, $\mathrm{x} 400$.

Transfection with small interference RNA (siRNA). All siRNAs were synthesized by Invitrogen (Thermo Fisher Scientific, Inc.), including the siRNA-IFN- $\beta$ for endogenous inhibition of IFN- $\beta$ (EI-IFN- $\beta$ ) and siRNA-vector. Osteoblasts $\left(1 \times 10^{6}\right)$ were transfected with 100 pmol siRNA-IFN- $\beta$ using Lipofectamine 2000 (Sigma-Aldrich; Merck KGaA), according to the manufacturer's protocol. While siRNA-vector transfection was performed in the control group.

Statistical analysis. All data are represented as the mean \pm standard error of triplicate experiments. Analysis was performing by SPSS software (version 14.0; SPSS, Inc., Chicago, IL, USA). Unpaired data were analyzed by Student's t-test, while comparisons of data between multiple groups were conducted by analysis of variance. $\mathrm{P}<0.05$ was considered as an indicator of a statistically significant difference.

\section{Results}

Effects of alendronate treatment on the viability, ALP activity and differentiation of osteoblasts. In order to analyze the efficacy of alendronate treatment on osteoporosis, the 
A

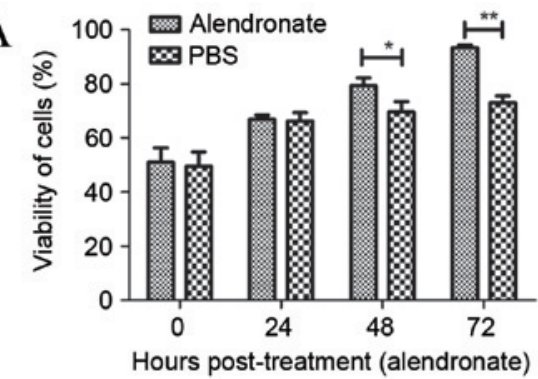

$\mathrm{C}$
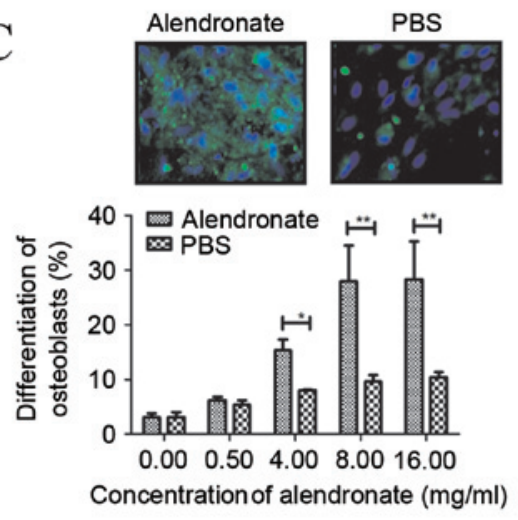

$\mathrm{E}$
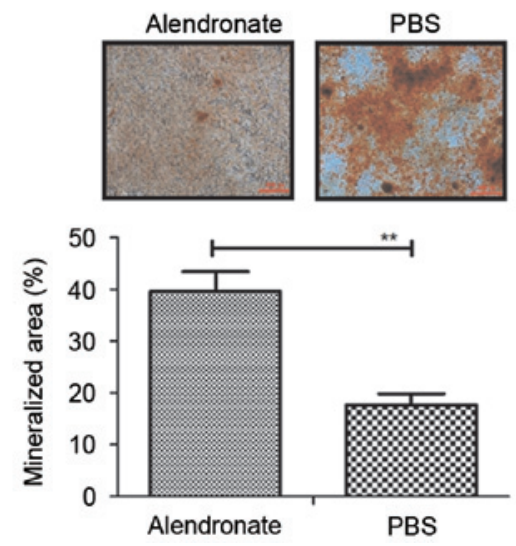

$\mathrm{B}$

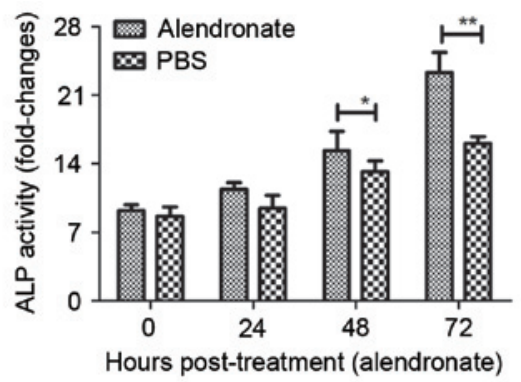

$\mathrm{D}$

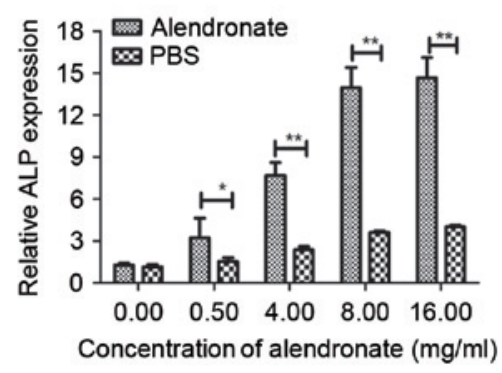

$\mathrm{F}$

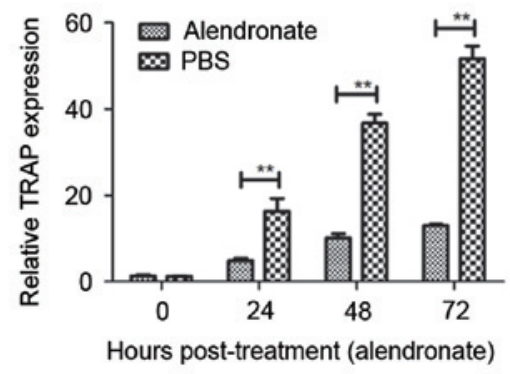

Figure 1. Viability, osteoblast ALP activity and differentiation of osteoblasts following treatment with alendronate. (A) Viability and (B) ALP activity in osteoblasts was markedly increased following incubation with alendronate for 48 and $72 \mathrm{~h}$. (C) Osteoblast differentiation was promoted by alendronate in a dose-dependent manner (representative images of $8 \mathrm{mg} / \mathrm{ml}$ treatment are shown). (D) mRNA expression of ALP, (E) osteoblastic mineralization determined by alizarin red $\mathrm{S}$ staining and $(\mathrm{F})$ mRNA expression of TRAP, following treatment with alendronate. The data are presented as the mean \pm standard error. ${ }^{*} \mathrm{P}<0.05$ and ${ }^{* *} \mathrm{P}<0.01$ alendronate vs. control (PBS) group. ALP, alkaline phosphatase; PBS, phosphate-buffered saline; TRAP, tartrate-resistant acid phosphatase.

ALP activity and differentiation of osteoblasts were analyzed following treatment with alendronate. It was observed that alendronate significantly increased the viability of osteoblasts after 48- and 72-h incubation (Fig. 1A). In addition, ALP activity was upregulated in osteoblasts subsequent to treatment with alendronate for 48 and $72 \mathrm{~h}$, as compared with the control group (Fig. 1B). It was also revealed that alendronate treatment at different concentrations $(0.5-16 \mathrm{mg} / \mathrm{ml})$ promoted early differentiation marker of osteoblasts derived from newborn rat calvaria determined by staining for ALP, with a significant effect observed at $\geq 4 \mathrm{mg} / \mathrm{ml}$ (Fig. 1C). Furthermore, the results indicated that alendronate $(0.5-16 \mathrm{mg} / \mathrm{ml})$ significantly enhanced ALP mRNA expression in osteoblasts (Fig. 1D). Alendronate treatment at $8 \mathrm{mg} / \mathrm{ml}$ markedly increased the mineralized area, as determined by alizarin red $\mathrm{S}$ staining for calcium (Fig. 1E). Notably, treatment with $8 \mathrm{mg} / \mathrm{ml}$ alendronate markedly decreased the mRNA expression levels of TRAP compared with those in the PBS-treated group (Fig. 1F). These results suggest that alendronate promotes osteoblast differentiation and bone formation.

Alendronate stimulates the expression levels of mRNAs associated with osteoblast differentiation. Next, the present study investigated the effects of alendronate on the mRNAs expression levels of osteoblast differentiation-associated factors in osteoblasts. It was observed that alendronate markedly promoted the mRNA expression levels of osteocalcin, osterix and Runx2, which are essential transcription factors for osteoblast differentiation (Fig. 2A-C). ODF, OPG and COL1A1 are essential for the osteoblast differentiation (35). As shown in Fig. 2D-F, alendronate stimulation also increased the expression levels of ODF, OPG and COL1A1 in osteoblasts. These results suggest that alendronate regulates osteoblast 
A

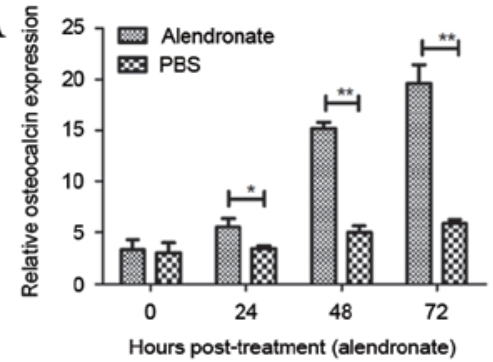

D

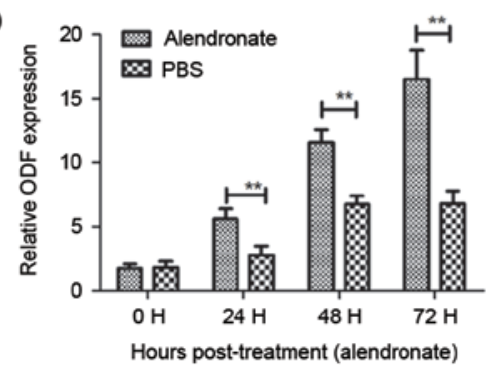

B

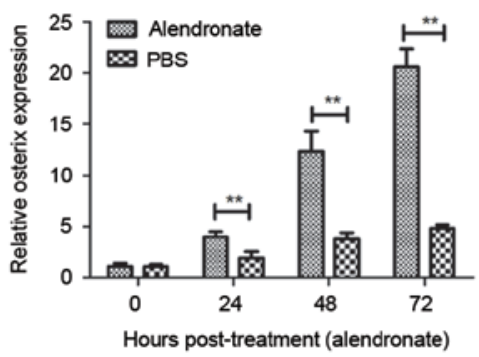

E

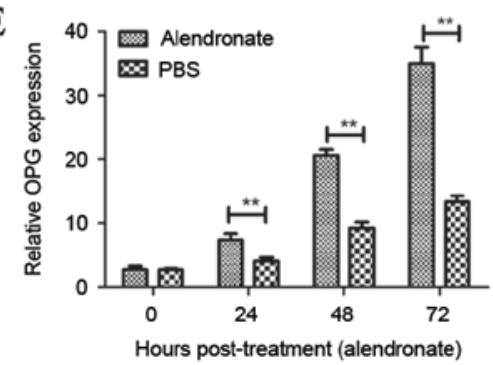

$\mathrm{C}$

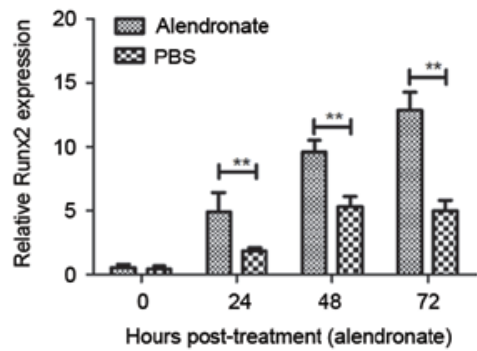

$\mathrm{F}$

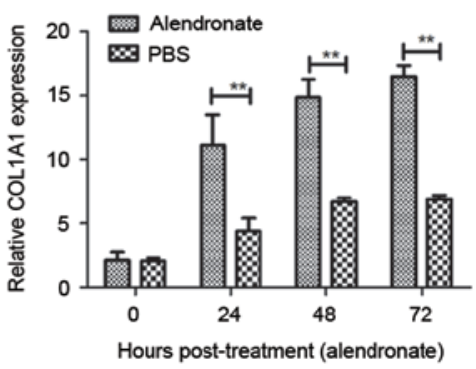

Figure 2. Analysis of alendronate-mediated osteoblast differentiation through the detection of the expression of osteoblast differentiation-associated genes. Alendronate stimulation increased the mRNA expression levels of (A) osteocalcin, (B) osterix, (C) Runx2, (D) ODF, (E) OPG and (F) COL1A1 in osteoblasts. The data are presented as the mean \pm standard error. ${ }^{*} \mathrm{P}<0.05$ and ${ }^{* *} \mathrm{P}<0.01$ alendronate vs. control (PBS) group. PBS, phosphate-buffered saline; Runx2, Runt-related transcription factor 2; ODF, osteoblast differentiation factor; OPG, osteoprotegerin; COL1A1, collagen 1A1.

differentiation by stimulating the expression levels of various mRNAs associated with osteoblast differentiation.

Resorption ability and TRAP activity of osteoclasts following treatment with alendronate. The resorption ability and TRAP activity of osteoclasts are essential for the progression of rarefaction of bone and function of bone tissue (36). The present study results demonstrated that alendronate treatment significantly inhibited the resorption ability of osteoclasts (Fig. 3A), but promoted the proliferation of osteoblasts during the differentiation period, as determined by toluidine blue staining (Fig. 3B). In addition, the TRAP activity of osteoclasts and osteoblasts following treatment with alendronate during the differentiation period was examined, and the results indicated that TRAP-positive cells were inhibited in osteoclasts and osteoblasts following treatment (Fig. 3C and D). Furthermore, TRAP activity in osteoclasts and osteoblasts was suppressed by the treatment of alendronate during the differentiation period when compared with non-treated cells (Fig. 3E and F). Taken together, these findings suggest that alendronate treatment markedly inhibits the resorption ability and TRAP activity of osteoclasts during the differentiation period, which may be beneficial for the treatment of osteoporosis.

Alendronate regulates osteoblast differentiation through the IFN- $\beta / S T A T 1$ signaling pathway. In order to analyze the molecular mechanism of alendronate-mediated osteoblast differentiation, the IFN- $\beta /$ STAT1 signaling pathway was investigated in osteoblasts. The results shown in Fig. 4A reveal that alendronate promoted IFN- $\beta$ expression in osteoblasts. It was also identified that STAT1 and pSTAT1 were enhanced in osteoblasts after treatment with alendronate (Fig. 4B). Alendronate treatment also increased the mRNA expression levels of Fra1, TRAF6 and SOCS1 in osteoblasts compared with the control group (Fig. 4C). However, endogenous inhibition of IFN- $\beta$ (EI-IFN- $\beta$ ) markedly reduced the inhibitory effects of alendronate (AEI-IFN- $\beta$ ) on osteoblast differentiation and differentiation-associated gene expression levels (Fig. 4D). In addition, inhibition of IFN- $\beta$ expression (EI-IFN- $\beta$ ) downregulated of STAT1 and pSTAT1 protein levels and abolished their upregulation induced by alendronate (AEI-IFN- $\beta$ ) in osteoblasts (Fig. 4E), which also reduced alendronate-promoted (AEI-IFN- $\beta$ ) expression levels of differentiation-associated genes, including osteocalcin, osterix and Runx2 (Fig. 4F). Taken together, these results revealed that alendronate treatment regulates osteoblast differentiation through upregulation of the IFN- $\beta / S T A T 1$ signaling pathway.

Alendronate treatment exerts a beneficial effect in rats with ovariectomy-induced osteoporosis, determined by histological. The current study further analyzed the therapeutic effects of alendronate on rats with ovariectomy-induced osteoporosis, which was determined by histological analysis of experimental rats on day 60 . The results in Fig. 5A revealed that bone structure was significantly improved in rats treated with alendronate that exhibited ovariectomy-induced osteoporosis compared with the PBS group. It was also observed that alendronate treatment prevented loss of trabeculae in rats with osteoporosis induced by ovariectomy (Fig. 5B). In addition, bone strength and bone density assays demonstrated that alendronate significantly improved osteoporosis in rats induced by ovariectomy, when compared with the PBS control group (Fig. 5C and D). Furthermore, the elastic modulus and post-yield displacement of bone were also increased in rats with osteoporosis following treatment with alendronate (Fig. 5E and F). Therefore, these data suggest that alendronate treatment was beneficial in rats with osteoporosis induced by ovariectomy, as determined by histological and index detection. 
A
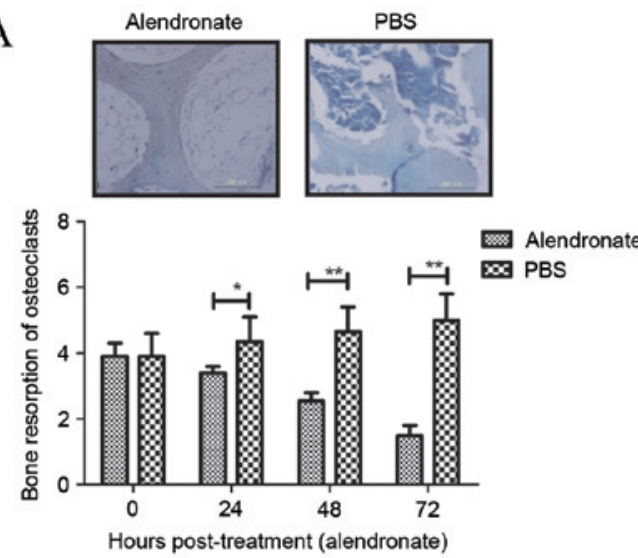

C

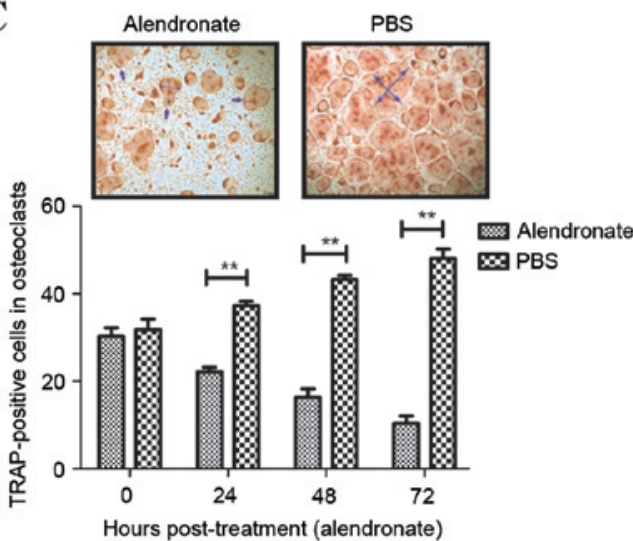

E

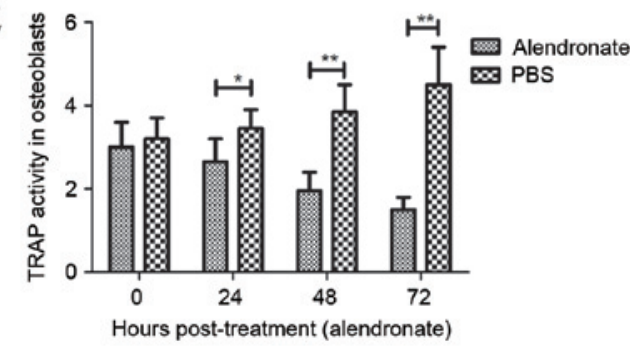

B
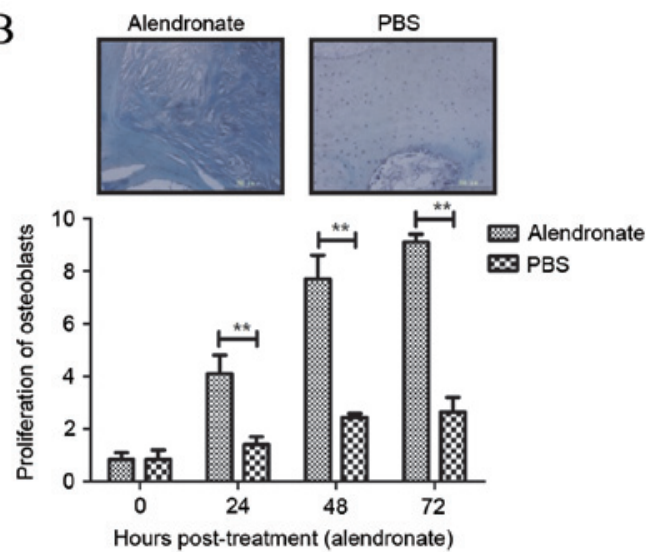

D
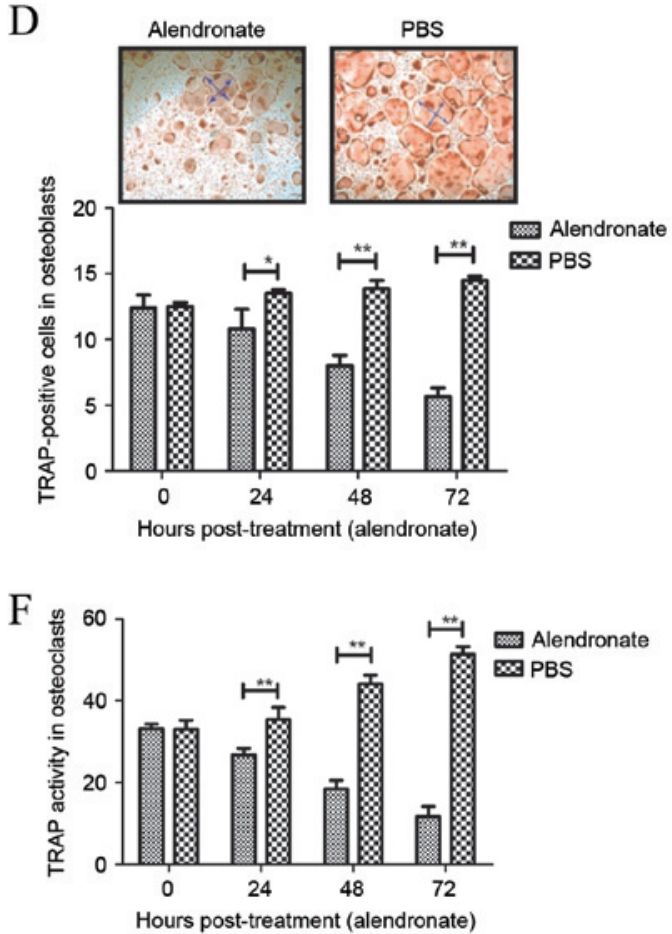

Figure 3. Bone resorption ability and TRAP activity of osteoclasts following treatment with alendronate. The bone resorption ability of (A) osteoclasts and (B) osteoblasts subsequent to alendronate treatment during the differentiation period was determined by toluidine blue staining. Alendronate regulates the number of TRAP-positive cells in (C) osteoclasts and (D) osteoblasts compared with the PBS control group. TRAP activity was also analyzed in (E) osteoblasts and (F) osteoclasts following treatment with alendronate or PBS. The data are presented as the mean \pm standard error. ${ }^{*} \mathrm{P}<0.05$ and ${ }^{* *} \mathrm{P}<0.01$ alendronate vs. control (PBS) group. PBS, phosphate-buffered saline; TRAP, tartrate-resistant acid phosphatase.

\section{Discussion}

Osteoporosis is identified as a systemic skeletal disease that affects mostly postmenopausal women characterized by reduction of bone strength and mass loss of bone mineral density (37,38). Evidence suggested that postmenopausal women have increased risk of osteoporosis, resulting in fragility fracture due to the lack of estrogen secretion $(39,40)$. Previous studies have also demonstrated that alendronate (a bisphosphonate) is an efficient agent for the treatment of osteoporosis, functioning through inhibition of bone resorption by accumulating on the bone surface and inhibition of osteoclast apoptosis $(41,42)$. In the present study, the therapeutic efficacy and potential underlying mechanism of alendronate treatment were investigated in a rat model of osteoporosis induced by ovariectomy. The presented results indicated that alendronate therapy promoted osteoblast differentiation in the calvarial osteoblastic cells isolated from newborn rats. In addition, the resorption ability and TRAP activity of osteoclasts were inhibited following treatment with alendronate, which may contribute to bone remodeling in rats with osteoporosis. Alendronate treatment stimulated ALP expression and activity, as well as the expression levels of mRNAs associated with osteoblast differentiation, including Fra1, TRAF6 and SOCS1. The expression levels of ODF, OPG and COL1A1 in osteoblasts were also upregulated in osteoblasts subsequent to alendronate administration. Furthermore, the findings of the current study indicated that alendronate treatment regulated the osteoblast differentiation through upregulation of IFN- $\beta$ /STAT1 signaling pathway.

A previous study has demonstrated that stimulation with IFN- $\beta$ leads to significant inhibition of osteoporotic 
A

\section{IFN- $\beta$}

$\beta$-actin

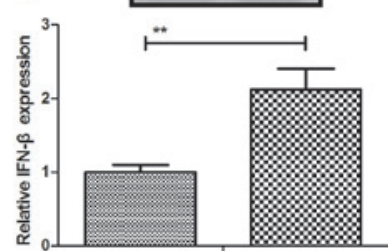

B

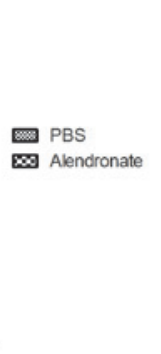

$\mathrm{D}$

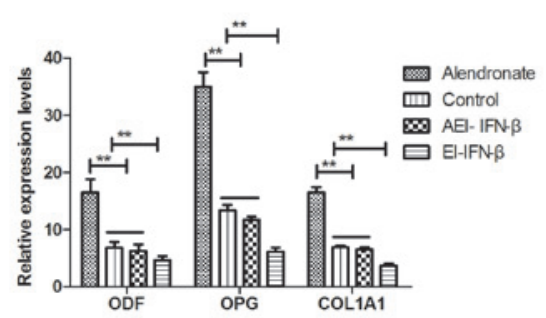

E

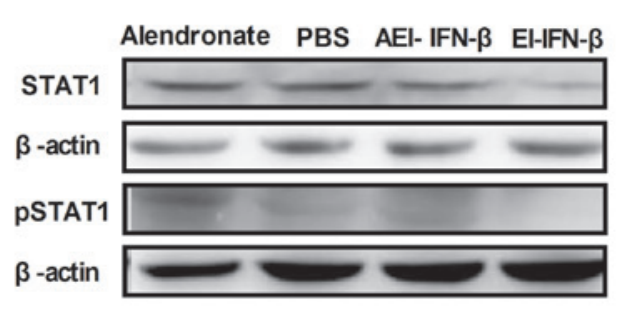

C

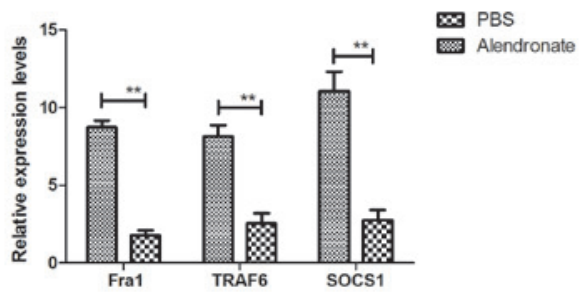

F

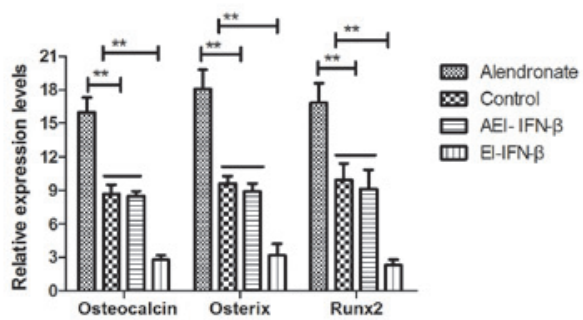

Figure 4. Alendronate regulates osteoblast differentiation through the IFN- $\beta / S T A T 1$ signaling pathway. (A) Alendronate promoted IFN- $\beta$ protein expression levels in osteoblasts. (B) Protein expression levels of STAT1 and pSTAT1 in osteoblasts following treatment with alendronate. (C) Analysis of mRNA expression levels of Fra1, TRAF6 and SOCS1 in osteoblasts. Inhibition of IFN- $\beta$ expression suppresses (D) ODF, OPG and COL1A1 expression levels, (E) STAT1 and pSTAT1 protein expression in osteoblasts, and (F) the differentiation-associated gene expression levels of osteocalcin, osterix and Runx2. The data are presented as the mean \pm standard error. ${ }^{* *} \mathrm{P}<0.01$ alendronate vs. control (PBS) group. PBS, phosphate-buffered saline; IFN- $\beta$, interferon- $\beta$; STAT1, signal transducer and activator of transcription 1; Fra1, Fos-related antigen 1; TRAF6, TNF-receptor-associated factor 6; SOCS1, suppressor of cytokine signaling 1; ODF, osteoblast differentiation factor; OPG, osteoprotegerin; COL1A1, collagen 1A1; Runx2, Runt-related transcription factor 2; EI-IFN- $\beta$, endogenous inhibition of IFN- $\beta$; AEI, alendronate + EI-IFN- $\beta$.

A

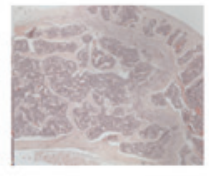

Alendronate

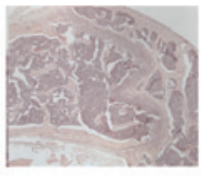

PBS

B

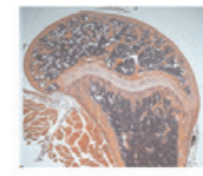

Alendronate

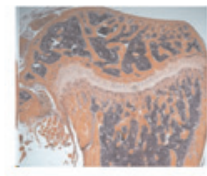

PBS
$\mathrm{C}$

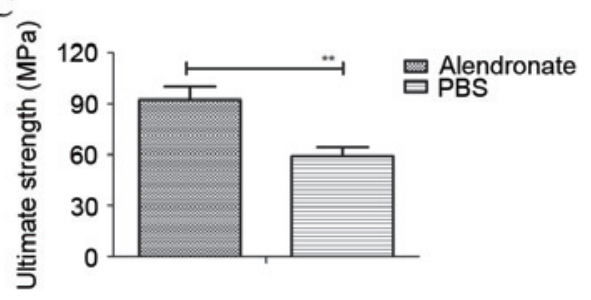

D

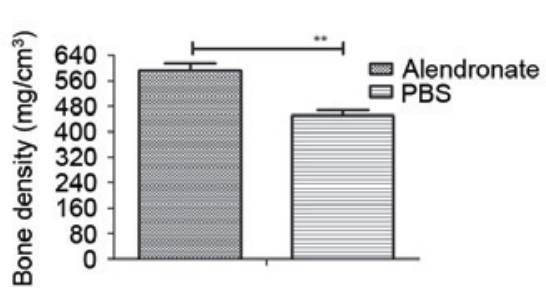

$\mathrm{E}$

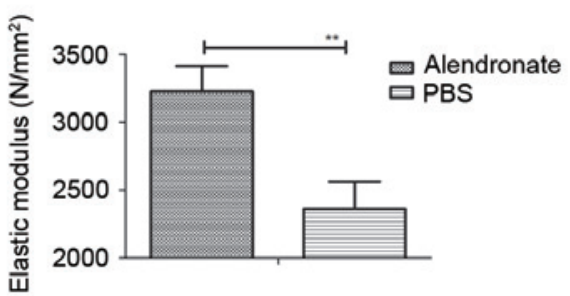

$\mathrm{F}$

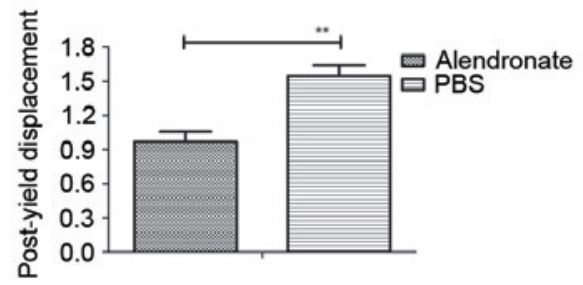

Figure 5. In vivo efficacy of alendronate for the treatment of rats with ovariectomy-induced osteoporosis. (A) Bone qualities analyzed by histological assay, (B) femur bone density, (C) bone strength, (D) bone density, (E) elastic modulus and (F) post-yield displacement were evaluated in rats with ovariectomy-induced osteoporosis following treatment with alendronate or PBS. The data are presented as the mean \pm standard error. ${ }^{* *} \mathrm{P}<0.01$ alendronate vs. control (PBS) group. PBS, phosphate-buffered saline.

osteoclasts (20). IFN- $\beta$ production is mainly secreted by fibroblasts, and subsequently binds to the IFN- $\alpha / \beta$ receptor $(43,44)$. The activity of IFN- $\beta$ depends on the transcriptional activator of the expression and phosphorylation of STAT1 and STAT2, which leads to the activation of the JAK signal pathway (45). Studies also indicated that IFN- $\beta /$ STAT1 signaling pathway regulates numerous metabolism disorder-associated molecular transcriptions (46-48). Additionally, IFN- $\beta$ functions as a potential drug for multiple sclerosis and exhibits various beneficial clinical outcomes $(49,50)$. In the present study, the involvement of the IFN- $\beta /$ STAT1 signaling pathway in osteoblast differentiation was analyzed. The results indicated that IFN- $\beta$ /STAT1 signaling pathway was enhanced in osteoporotic osteoblasts, resulting in the increase 
of Fra1, TRAF6 and SOCS1 expression levels following treatment with alendronate. Furthermore, alendronate increased the differentiation-associated gene expression levels of osteocalcin, osterix and Runx 2 through upregulation of IFN- $\beta$ and enhanced the phosphorylated production of IFN- $\beta$. However, inhibition of IFN- $\beta$ expression also suppressed STAT1 and pSTAT1 expression in osteoblasts. These findings indicated that alendronate mediated improvements in osteoporosis through regulation of IFN- $\beta /$ STAT1 signaling pathway in osteoblasts.

Bone strength and bone density are the most important indicatorsin the progression of patients withosteoporosis $(51,52)$. Various types of treatments in ovariectomized rats have been investigated in a large number of studies (53-55). In addition, histological analysis of bone qualities is essential for examining the improvement of osteoporosis, which is regarded as an evaluation criterion for drugs used in the treatment of osteoporosis $(56,57)$. In the present study, the therapeutic effects of alendronate-mediated improvements of osteoporosis were investigated by histological analysis, including examining the bone density and loss of trabeculae. The present study findings also indicated that bone strength, bone density, elastic modulus and post-yield displacement were significantly improved following treatment with alendronate in rats with osteoporosis induced by ovariectomy.

In conclusion, although numerous reports have provided important evidence for identifying the efficacy of alendronate treatment in osteoblast differentiation, the underlying molecular mechanism remains poorly understood $(58,59)$. In the present study, it was demonstrated that alendronate treatment not only presents stimulatory effects on osteoblast differentiation and mineralization, but also enhances the bone formation in rats with osteoporosis induced by ovariectomy. The findings also revealed that alendronate improves bone loss of osteoporosis through upregulation of the IFN- $\beta$ /STAT1 signaling pathway, which suggests that alendronate may be a potential therapeutic agent for osteoporosis.

\section{References}

1. Wong SK, Chin KY, Suhaimi FH, Ahmad F and Ima-Nirwana S: The Relationship between metabolic syndrome and osteoporosis: A Review. Nutrients 8: pii: E347, 2016.

2. Petty SJ, Wilding H and Wark JD: Osteoporosis associated with epilepsy and the use of anti-epileptics-a review. Curr osteoporos Rep 14: 54-65, 2016.

3. Newman M, Minns Lowe C and Barker K: Spinal orthoses for vertebral osteoporosis and osteoporotic vertebral fracture: A systematic review. Arch Phys Med Rehabil 97: 1013-1025, 2016.

4. Gennari L, Merlotti D, De Paola V, Calabrò A, Becherini L, Martini G and Nuti R: Estrogen receptor gene polymorphisms and the genetics of osteoporosis: A HuGE review. Am J Epidemiol 161: 307-320, 2005.

5. Bushardt RL, Turner JL, Ragucci KR and Askins DG Jr: Non-estrogen treatments for osteoporosis: An evidence-based review. JAAPA 19: 25-30, 2006.

6. Ziablitsev DS and Larin OS: Influence of single nucleotide polymorphisms of vitamin D receptor-gene on the level of osteoassociated hormones linkage with postmenopausal osteoporosis. Fiziol Zh 61: 21-27, 2015.

7. Dempster DW, Zhou H, Recker RR, Brown JP, Bolognese MA, Recknor CP, Kendler DL,Lewiecki EM,Hanley DA, Rao SD, et al: A longitudinal study of skeletal histomorphometry at 6 and 24 months across four bone envelopes in postmenopausal women with osteoporosis receiving teriparatide or zoledronic acid in the SHOTZ Trial. J Bone Miner Res 31: 1429-1439, 2016.
8. Iba K, Sonoda T, Takada J, Dohke T and Yamashita T: Further significant effects of eldecalcitol on bone resorption markers and bone mineral density in postmenopausal osteoporosis patients having undergone long-term bisphosphonate treatment. J Bone Miner Metab 35: 171-176, 2017.

9. Darba J, Kaskens L, Sorio Vilela F and Lothgren M: Cost-utility of denosumab for the treatment of postmenopausal osteoporosis in Spain. Clinicoecon Outcomes Res 7: 105-117, 2015.

10. Inderjeeth CA, Glendenning P, Ratnagobal S, Inderjeeth DC and Ondhia C: Long-term efficacy, safety, and patient acceptability of ibandronate in the treatment of postmenopausal osteoporosis. Int J Womens Health 7: 7-17, 2014.

11. Huang ZB, Wan SL, Lu YJ, Ning L, Liu C and Fan SW: Does vitamin K2 play a role in the prevention and treatment of osteoporosis for postmenopausal women: A meta-analysis of randomized controlled trials. Osteoporos Int 26: 1175-1186, 2015.

12. Ouyang L, Zhang Q, Ruan X, Feng Y and Wang X: Treatment effect of Bushen Huayu extract on postmenopausal osteoporosis in vivo. Exp Ther Med 7: 1687-1690, 2014.

13. Zhdan VM, Kitura O, Kitura IeM, Babanina $M$ and Tkachenko MV: Treatment of postmenopausal osteoporosis in the general medical practice (clinical case). Lik Sprava: 85-89, 2013.

14. Massafra U, Integlia D, Broccoli S and Migliore A: Mixed treatment comparison to rank antiresorptive agents in preventing new non vertebral fractures in postmenopausal osteoporosis. Value Health 18: A636, 2015.

15. Hassler N, Gamsjaeger S, Hofstetter B, Brozek W, Klaushofer K and Paschalis EP: Effects of long-term alendronate treatment on postmenopausal osteoporosis bone material properties. Osteoporos Int 26: 339-352, 2015.

16. Igase M, Kohara K, Tabara Y, Ohara M, Takita R, Ochi M, Okada Y and Miki T: Change in arterial stiffness associated with monthly bisphosphonate treatment in women with postmenopausal osteoporosis. Menopause 21: 962-966, 2014.

17. Celer O, Akalin A and Oztunali C: Effect of teriparatide treatment on endothelial function, glucose metabolism and inflammation markers in patients with postmenopausal osteoporosis. Clin Endocrinol (Oxf) 85: 556-560, 2016

18. Rugpolmuang L and Waikakul S: Effect of a short-term treatment with once-a-week medication of alendronate $70 \mathrm{Mg}$ on bone turnover markers in postmenopausal women with osteoporosis. J Med Assoc Thai 98 (Suppl 8): S70-S75, 2015.

19. Schultz TC, Valenzano JP, Verzella JL and Umland EM: Odanacatib: An emerging novel treatment alternative for postmenopausal osteoporosis. Womens Health (Lond) 11: 805-814, 2015.

20. Seeliger C, Schyschka L, KronbachZ, Wottge A, van Griensven M, Wildemann B and Vester H: Signaling pathway STAT1 is strongly activated by IFN- $\beta$ in the pathogenesis of osteoporosis. Eur J Med Res 20: 1, 2015.

21. Chen XD, Xiao P, Lei SF, Liu YZ, Guo YF, Deng FY, Tan LJ, Zhu XZ, Chen FR, Recker RR and Deng HW: Gene expression profiling in monocytes and SNP association suggest the importance of the STAT1 gene for osteoporosis in both Chinese and Caucasians. J Bone Miner Res 25: 339-355, 2010.

22. Kushwaha P, Khedgikar V, Ahmad N, Karvande A, Gautam J, Kumar P, Maurya R and Trivedi R: A neoflavonoid dalsissooal isolated from heartwood of Dalbergia sissoo Roxb. Has bone forming effects in mice model for osteoporosis. Eur J Pharmacol 788: 65-74, 2016.

23. Papamanthos M, Varitimidis S, Dailiana ZH, Kogia E and Malizos K: Computer-assisted evaluation of Mandibular Cortical Width (MCW) index as an indicator of osteoporosis. Hippokratia 18: 251-257, 2014.

24. Shum LC, White NS, Nadtochiy SM, Bentley KL, Brookes PS, Jonason JH and Eliseev RA: Cyclophilin D Knock-out mice show enhanced resistance to osteoporosis and to metabolic changes observed in aging bone. PLoS One 11: e0155709, 2016.

25. Cao H, Nazarian A, Ackerman JL, Snyder BD, Rosenberg AE, Nazarian RM, Hrovat MI, Dai G, Mintzopoulos D and Wu Y: Quantitative (31)P NMR spectroscopy and (1)H MRI measurements of bone mineral and matrix density differentiate metabolic bone diseases in rat models. Bone 46: 1582-1590, 2010.

26. McCann RM, Colleary G, Geddis C, Clarke SA, Jordan GR, Dickson GR and Marsh D: Effect of osteoporosis on bone mineral density and fracture repair in a rat femoral fracture model. J Orthop Res 26: 384-393, 2008. 
27. Leamy LJ, Kelly SA, Hua K, Farber CR and Pomp D Quantitative trait loci for bone mineral density and femoral morphology in an advanced intercross population of mice. Bone 55: 222-229, 2013.

28. Jonason JH and O'Keefe RJ: Isolation and culture of neonatal mouse calvarial osteoblasts. Methods Mol Biol 1130: 295-305, 2014.

29. Saiyed ZM, Sharma S, Godawat R, Telang SD and Ramchand CN: Activity and stability of alkaline phosphatase (ALP) immobilized onto magnetic nanoparticles (Fe3O4). J Biotechnol 131: 240-244, 2007.

30. Subramanian K, Geraerts M, Pauwelyn KA, Park Y, Owens DJ, Muijtjens M, Ulloa-Montoya F, Jiang Y, Verfaillie CM and $\mathrm{Hu}$ WS: Isolation procedure and characterization of multipotent adult progenitor cells from rat bone marrow. Methods Mol Biol 636: 55-78, 2010.

31. Idris AI, Landao-Bassonga E and Ralston SH: The TRPV1 ion channel antagonist capsazepine inhibits osteoclast and osteoblast differentiation in vitro and ovariectomy induced bone loss in vivo. Bone 46: 1089-1099, 2010

32. Hiemer B, Ziebart J, Jonitz-Heincke A, Grunert PC, Su Y, Hansmann D and Bader R: Magnetically induced electrostimulation of human osteoblasts results in enhanced cell viability and osteogenic differentiation. Int J Mol Med 38: 57-64, 2016

33. Xiao S, Wang $J$ and Xiao N: MicroRNAs as noninvasive biomarkers in bladder cancer detection: A diagnostic meta-analysis based on qRT-PCR data. Int J Biol Markers 31 e276-e285, 2016

34. Wai-Hoe L, Wing-Seng L, Ismail Z and Lay-Harn G SDS-PAGE-based quantitative assay for screening of kidney stone disease. Biol Proced Online 11: 145-160, 2009.

35. Johnson RW, White JD, Walker EC, Martin TJ and Sims NA: Myokines (muscle-derived cytokines and chemokines) including ciliary neurotrophic factor (CNTF) inhibit osteoblast differentiation. Bone 64: 47-56, 2014.

36. Takahashi M, Kushida K, Kawana K, Hoshino H and Inoue T: Discrimination ability of pyridinoline crosslinks related markers for bone resorption in postmenopause and osteoporosis. Endocr Res 23: 105-117, 1997

37. Ma J, Ma Y, Liu X, Chen S, Liu C, Qin A and Fan S: Gambogic acid inhibits osteoclast formation and ovariectomy-induced osteoporosis by suppressing the JNK, p38 and Akt signalling pathways. Biochem J 469: 399-408, 2015.

38. Song SH, Wang D, Mo YY, Ding C and Shang P: Antiosteoporotic effects of naringenin on ovariectomy-induced osteoporosis in rat. Yao Xue Xue Bao 50: 154-161, 2015 (In Chinese).

39. Lee SN, Cho JY, Eun YM, Song SW and Moon KW: Associations between osteoporosis and coronary artery disease in postmenopausal women. Climacteric 19: 458-462, 2016

40. Alami S, Hervouet L, Poiraudeau S, Briot K and Roux C: Barriers to effective postmenopausal osteoporosis treatment: A qualitative study of patients' and practitioners' views. PLoS One 11: e0158365, 2016.

41. Karlsson L, Lundkvist J, Psachoulia E, Intorcia M and Ström O Persistence with denosumab and persistence with oral bisphosphonates for the treatment of postmenopausal osteoporosis: A retrospective, observational study, and a meta-analysis Osteoporos Int 26: 2401-2411, 2015.

42. Kim MJ, Kim SN, Lee IS, Chung S, Lee J, Yang Y, Lee I and Koh SE: Effects of bisphosphonates to treat osteoporosis in children with cerebral palsy: A meta-analysis. J Pediatr Endocrinol Metab 28: 1343-1350, 2015.

43. Diringer MN, Dhar R, Scalfani M, Zazulia AR, Chicoine M, Powers WJ and Derdeyn CP: Effect of high-dose simvastatin on cerebral blood flow and static autoregulation in subarachnoid hemorrhage. Neurocrit Care 25: 56-63, 2016.

44. Dauletbaev N, Cammisano M, Herscovitch K and Lands LC: Stimulation of the RIG-I/MAVS Pathway by polyinosinic: Polycytidylic acid upregulates IFN- $\beta$ in airway epithelial cells with minimal costimulation of IL-8. J Immunol 195: 2829-2841, 2015.

45. Grumbach IM, Fish EN, Uddin S, Majchrzak B, Colamonici OR, Figulla HR, Heim A and Platanias LC: Activation of the Jak-Stat pathway in cells that exhibit selective sensitivity to the antivira effects of IFN-beta compared with IFN-alpha. J Interferon Cytokine Res 19: 797-801, 1999.
46. Imaizumi $\mathrm{T}$, Yoshida H, Hayakari R, Xing F, Wang L, Matsumiya T, Tanji K, Kawaguchi S, Murakami M and Tanaka H: Interferon-stimulated gene (ISG) 60, as well as ISG56 and ISG54, positively regulates TLR3/IFN- $\beta$ /STAT1 axis in U373MG human astrocytoma cells. Neurosci Res 105: 35-41, 2016.

47. Ma JS, Kim WJ, Kim JJ, Kim TJ, Ye SK, Song MD, Kang H, Kim DW, Moon WK and Lee KH: Gold nanoparticles attenuate LPS-induced NO production through the inhibition of NF-kappaB and IFN-beta/STAT1 pathways in RAW264.7 cells Nitric Oxide 23: 214-219, 2010

48. Yun CH, Yang JS, Kang SS, Yang Y, Cho JH, Son CG and Han SH: NF-kappaB signaling pathway, not IFN-beta/STAT1, is responsible for the selenium suppression of LPS-induced nitric oxide production. Int immunopharmacol 7: 1192-1198, 2007.

49. Bustamante MF, Morcillo-Suárez C, Malhotra S, Rio J, Leyva L, Fernández O, Zettl UK, Killestein J, Brassat D, García-Merino JA, et al: Pharmacogenomic study in patients with multiple sclerosis: Responders and nonresponders to IFN- $\beta$. Neurol Neuroimmunol Neuroinflamm 2: e154, 2015.

50. Damiano S, Sasso A, De Felice B, Terrazzano G, Bresciamorra V, Carotenuto A, Orefice NS, Orefice G, Vacca G, Belfiore A, et al: The IFN- $\beta$ lb effect on $\mathrm{Cu} \mathrm{Zn}$ superoxide dismutase (SOD1) in peripheral mononuclear blood cells of relapsing-remitting multiple sclerosis patients and in neuroblastoma SK-N-BE cells. Brain Res Bull 118: 1-6, 2015.

51. Takahashi T, Watanabe T, Nakada H, Tanimoto Y, Kimoto S, Mijares DQ, Zhang Y and Kawai Y: Effect of a dietary supplement on peri-implant bone strength in a rat model of osteoporosis. J Prosthodont Res 60: 131-137, 2016.

52. Li X, Niu QT, Warmington KS, Asuncion FJ, DwyerD, Grisanti M, Han CY, Stolina M, Eschenberg MJ, Kostenuik PJ, et al: Progressive increases in bone mass and bone strength in an ovariectomized rat model of osteoporosis after 26 weeks of treatment with a sclerostin antibody. Endocrinology 155: 4785-4797, 2014.

53. Brennan O, Kuliwaba JS, Lee TC, Parkinson IH, Fazzalari NL, McNamara LM and O'Brien FJ: Temporal changes in bone composition, architecture, and strength following estrogen deficiency in osteoporosis. Calcif Tissue Int 91: 440-449, 2012.

54. Ying SH, Kao HC, Chang MC, Yu WK, Wang ST and Liu CL: Fixation strength of PMMA-augmented pedicle screws after depth adjustment in a synthetic bone model of osteoporosis. Orthopedics 35: e1511-e1516, 2012

55. Simon JA, Recknor C, Moffett AH Jr, Adachi JD, Franek E, Lewiecki EM, McClung MR, Mautalen CA, Ragi-Eis S, Nicholson GC, et al: Impact of denosumab on the peripheral skeleton of postmenopausal women with osteoporosis: Bone density, mass, and strength of the radius, and wrist fracture. Menopause 20: 130-137, 2013.

56. Mashiba T: Morphological analysis of bone dynamics and metabolic bone disease. Histological findings in animal fracture model-effects of osteoporosis treatment drugs on fracture healing process. Clin Calcium 21: 551-558, 2011 (In Japanese).

57. Delling G, Ritzel H and Werner M: Histological characteristics and prevalence of secondary osteoporosis in systemic mastocytosis. A retrospective analysis of 158 cases. Pathologe 22: 132-140, 2001 (In German).

58. Saag KG, Agnusdei D, Hans D, Kohlmeier LA, Krohn KD, Leib ES, MacLaughlin EJ, Alam J, Simonelli C, Taylor KA and Marcus R: Trabecular bone score in patients with chronic glucocorticoid-induced osteoporosis treated with alendronate or teriparatide. Arthritis Rheumatol 68: 2122-2128, 2016.

59. Ryu TK, Kang RH, Jeong KY, Jun DR, Koh JM, Kim D, Bae SK and Choi SW: Bone-targeted delivery of nanodiamond-based drug carriers conjugated with alendronate for potential osteoporosis treatment. J Control Release 232: 152-160, 2016.

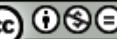

This work is licensed under a Creative Commons Attribution-NonCommercial-NoDerivatives 4.0 International (CC BY-NC-ND 4.0) License. 